\title{
El mundo paralelo de la sociedad virtual
}

María José Ulin Alberto

Universidad Don Bosco

Resumen: El presente artículo académico pretende analizar a grandes rasgos el paradigma construido sobre la representación de la sociedad virtual en la cual conviven dos tipos de usuarios: los nativos (millennials) y los migrantes digitales. Para ello se muestra un contraste entre la publicidad global y local contemporánea de enseres y servicios tecnológicos en línea. La hipótesis de este artículo supone a la publicidad como una mediación entre la manera de entender el mundo y la manera de construirlo. Es en esta construcción de mundo que la publicidad pretende mostrar un nuevo paradigma de sociedad: una sociedad altamente tecnificada, civilizada y en ocasiones perfecta. Sin embargo, el análisis discursivo del mensaje publicitario brinda connotaciones de una sociedad cimentada en una estructura ortodoxa, conservadora y mítica, en la cual los enseres y servicios tecnológicos solamente son un elemento cosmético de la cibercultura.

Abstract: This academic paper aims to analize roughly the paradigm that has been built about the representation of the virtual society, in which two types of users coexist: native (millennials) and digital migrants. The article's hypothesis suposses that the advertising is a mediation between the way to understand the world and the way it is built. In this construction of the world the advertising pretends to show a new society's paradigm: a high-tech, civilized and in certain occasions a perfect society. However, the analysis of the advertising speech provides a glance of the connotations of a society that has an orthodox, conservative and mythical structure, in which products and technological services are just a cosmetic element of the cyberculture.

Palabras claves: Sociedad Virtual, publicidad, medios digitales, cibercultura, comunicación masiva, nuevas tecnologías

Key Words: Virtual society, advertising, digital media, cyberculture, mass communication, new technologies 


\section{Introducción}

La construcción de mundo que proporciona la publicidad en línea de enseres y servicios tecnológicos a nivel mundial establece el paradigma ideal de "un mundo sin fronteras" en el que internet ha pasado de ser una simple herramienta a constituir "la forma de ser". En este mundo conviven dos modelos de usuarios: el primero los nativos digitales ${ }^{1}$ o millennials, los cuales son niños y jóvenes quienes usan de manera instintiva la tecnología. El término nativo digital hace referencia a aquellas personas que han nacido y se han formado utilizando la particular "lengua digital" de juegos por ordenador, video e internet (Prensky, 2010). Por otra parte, el término millennial hace referencia a la generación de niños nacidos en los ochentas que conforman la "generación del milenio" a partir del año 2000. El segundo modelo de usuario lo conforman los migrantes digitales $^{2}$ los cuales son adultos que han tenido que adaptar su modo de vida a esta realidad, el término migrante digital hace referencia a aquellas personas que no nacieron en entornos de uso cotidiano de la tecnología pero han tenido que sufrir un proceso de adaptación al entorno y al ambiente, conservando un "acento" con el pasado (Prensky, 2010). Sin embargo, a pesar de tener diferentes competencias de aprendizaje tecnológico estos usuarios, ambos pueden estar comunicados a toda hora, desde cualquier lugar, por lo que se les atribuye las características del ser "omnipresente" y del ser "multitasking".

La publicidad en línea de los emporios tecnológicos globales y locales más consumidos en los últimos años refleja en parte esta realidad. El mensaje narrado en los spots publicitarios de estas empresas presenta a la tecnología ligada a internet como una herramienta que, además de facilitar procesos, muestra a estos dos usuarios (nativos y migrantes digitales) inmersos en una nueva manera de actuar y sentir en esta construcción paradigmática de "un mundo sin fronteras" y en el cual las posibilidades de realización son ilimitadas, siendo ellos diferenciados sutilmente por la forma de utilizar los enseres y servicios. Sin embargo, es conveniente analizar si estos sistemas de construcción de mundo son sistemas de transformación dentro de la narrativa, o si lo presentado en este mundo subyacente (paralelo) establece un Sistema Mundo ${ }^{3}$ construido de manera estética, presentando en la lectura del subtexto un "aparente" cambio paradigma, convirtiéndose así en construcciones de mundo conservadoras y hegemónicas.

Para la realización de este análisis de índole semiótico se ha tomado en cuenta la participación evidente de los dos usuarios 
referidos en el estudio. Se analiza la muestra de cuatro spots publicitarios, siendo dos de ellos pertenecientes a una de las marcas de enseres tecnológicos más consumidas a nivel global, así como dos spots publicitarios pertenecientes a telefonías locales salvadoreñas. realizar los siguientes cuestionamientos: ¿la tecnología presenta realmente cambios paradigmáticos en el Sistema Mundo de la sociedad global y local? o, por el contrario, ¿estos usuarios replican modelos de mundo pertenecientes a un régimen legitimador y ortodoxo?

\section{La madre consumista que traslada su actividad análoga a un medio digital}

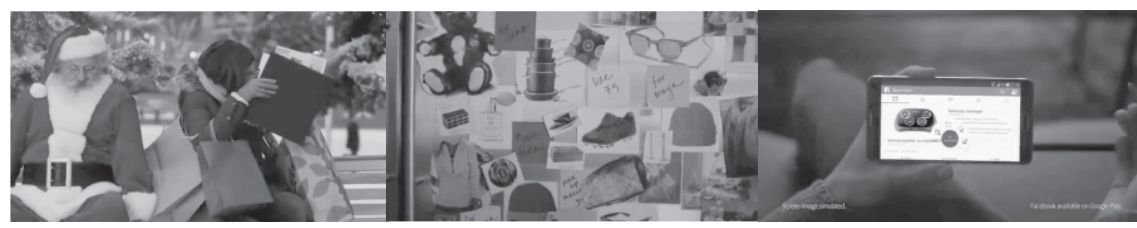

Nota: Emblema de la mujer consumista. Los paquetes que almacenan las compras representan la actividad de consumo por parte del personaje. Además, el significado del emblema se ve respaldado por la época enfatizada por Papá Noel a la izquierda.
Nota: Evidencia de la actividad análoga realizada por la madre para realizar las compras navideñas, la cual consiste en realizar un moodboard (tablero de imágenes) en la refrigeradora. En este moodboard ella detalla medidas y destinatarios de los obsequios.
Nota: Evidencia de la condición de migrante digital de la madre. El traslado de la actividad análoga al dispositivo móvil por medio de una aplicación. Ahora, ella puede buscar, seleccionar y comprar los obsequios a sus familiares en navidad.
Para el caso del anuncio del Smartphone Galaxy Note 4 titulado: Do you note? My mom sure knows how to shop smart!, (Samsung Mobile, 2014a) se presenta la condición socio-simbólica ${ }^{4}$ de una migrante digital/global, la cual rondará por los cuarenta años de edad y quien en plena navidad es un caos a la hora de comprar los obsequios para su familia. Ella es un símbolo de feminidad, entendido como el emblema ${ }^{5}$ de la mujer consumista que va de vitrina en vitrina cargada de bolsas de diferentes almacenes.
Ella convive con el estrés de su rutina en la búsqueda del regalo adecuado para cada uno de los miembros de su familia en la época de más consumo en Occidente: la Navidad. Sin embargo, no es una mujer consumista-egoísta; es una mujer consumista insertada en el rol de madre, y es en esta construcción donde se adjudica por rol femenino y materno el compromiso de dar un presente agradable y único a cada miembro de su familia. El personaje se ve envuelto en la frustración e insatisfacción de no encontrar el 
regalo perfecto para cada familiar. El desorden ${ }^{6}$ en su lista de compras (visibilizado en los espacios estereotipados para el personaje: la mesa del comedor, la puerta del refrigerador y en la sala de su hogar) hace que incurra en una solución a su problema; para el siguiente año en la misma época, ella "usaría su nuevo teléfono para solo seleccionar lo que quiere comprar", haciendo evidente el traslado de la actividad que originalmente se realizaba de manera análoga por medio de papeles pegados en cualquier lado, a un enser digital compacto de fácil uso gracias a las aplicaciones móviles, el que incluso relega a la complicada y poco eficiente computadora portátil, la que irónicamente hace algunos años parecía ser un enser innovador. El personaje alcanza en la narrativa su ideal de deseo:" "ella tiene todo en un solo lugar para realizar sus compras" y así "ella puede tener una navidad pacífica al igual que el resto de la familia". Esta construcción de migrante digital es validada por el hijo menor de la familia (quien es un nativo digital evidente). Durante el spot publicitario, la voz en off del niño va narrando la historia, y es este personaje el que tácitamente da a conocer que su madre "seguramente" conoce cómo comprar inteligentemente por medio de la opción: selección inteligente del móvil Galaxy Note 4.

\section{Tabla 1. Registro del código audiovisual}

\begin{tabular}{|c|c|c|c|c|c|c|}
\hline \multirow[b]{2}{*}{ Personaje } & \multirow[b]{2}{*}{ Espacio } & \multirow[b]{2}{*}{$\begin{array}{c}\text { Características de } \\
\text { migrante digital }\end{array}$} & \multirow[b]{2}{*}{$\begin{array}{l}\text { Características de } \\
\text { nativo digital } \\
\text { (millennial) }\end{array}$} & \multicolumn{3}{|c|}{ Condiciones de mundo } \\
\hline & & & & $\begin{array}{l}\text { Símbolos } \\
\text { rutinarios } \\
\text { del régimen } \\
\text { ortodoxo }\end{array}$ & $\begin{array}{l}\text { Símbolos } \\
\text { rutinarios del } \\
\text { régimen que } \\
\text { aparentemente } \\
\text { cuestiona la } \\
\text { autoridad }\end{array}$ & $\begin{array}{l}\text { Símbolos } \\
\text { rutinarios del } \\
\text { régimen que } \\
\text { cambia de } \\
\text { estructura }\end{array}$ \\
\hline Madre & $\begin{array}{l}\text { - Urbano } \\
\text { - Centro } \\
\text { comercial, } \\
\text { casa (mesa del } \\
\text { comedor, puerta } \\
\text { del frigoríico, } \\
\text { sala de la casa). }\end{array}$ & $\begin{array}{l}\text { Traslada la actividad } \\
\text { que originalmente la } \\
\text { realizaba de manera } \\
\text { análoga por medio de } \\
\text { papeles pegados en } \\
\text { cualquier lado (que } \\
\text { generaba el desorden } \\
\text { y la frustración) a la } \\
\text { app de su teléfono } \\
\text { móvil,la cual le } \\
\text { permite hacer un } \\
\text { scrapbook virtual, } \\
\text { ordenando así su } \\
\text { tarea encomendada } \\
\text { por rol femenino: } \\
\text { las compras para } \\
\text { cada uno de } \\
\text { los integrantes } \\
\text { familiares. }\end{array}$ & & $\begin{array}{l}\text { Figura femenina } \\
\text { emblema de la } \\
\text { mujer consumista, } \\
\text { su razón de ser es } \\
\text { comprar el objeto } \\
\text { perfecto para } \\
\text { cada integrante } \\
\text { de su familia. } \\
\text { Figura femenina } \\
\text { emblema de } \\
\text { la maternidad. } \\
\text { El personaje } \\
\text { revela por medio } \\
\text { del vínculo } \\
\text { afectivo con los } \\
\text { integrantes de la } \\
\text { familia, el interés } \\
\text { de llenarles de } \\
\text { detalles. }\end{array}$ & & \\
\hline
\end{tabular}




\begin{tabular}{|c|c|c|c|c|c|c|}
\hline \multirow[b]{2}{*}{ Personaje } & \multirow[b]{2}{*}{ Espacio } & \multirow[b]{2}{*}{$\begin{array}{l}\text { Características de } \\
\text { migrante digital }\end{array}$} & \multirow[b]{2}{*}{$\begin{array}{l}\text { Características de } \\
\text { nativo digital } \\
\text { (millennial) }\end{array}$} & \multicolumn{3}{|c|}{ Condiciones de mundo } \\
\hline & & & & $\begin{array}{l}\text { Símbolos } \\
\text { rutinarios } \\
\text { del régimen } \\
\text { ortodoxo }\end{array}$ & $\begin{array}{l}\text { Símbolos } \\
\text { rutinarios del } \\
\text { régimen que } \\
\text { aparentemente } \\
\text { cuestiona la } \\
\text { autoridad }\end{array}$ & $\begin{array}{l}\text { Símbolos } \\
\text { rutinarios del } \\
\text { régimen que } \\
\text { cambia de } \\
\text { estructura }\end{array}$ \\
\hline Hijo & $\begin{array}{l}\text { Urbano. Aunque } \\
\text { está de manera } \\
\text { omnipresente } \\
\text { en el relato } \\
\text { debido a que es } \\
\text { el narrador. }\end{array}$ & & $\begin{array}{l}\text { Valida la } \\
\text { condición de } \\
\text { migrante digital } \\
\text { a la madre: "ella } \\
\text { de seguro conoce } \\
\text { cómo comprar } \\
\text { inteligentemente", } \\
\text { (haciendo } \\
\text { referencia } \\
\text { al teléfono } \\
\text { inteligente como } \\
\text { herramienta de } \\
\text { compra en línea). }\end{array}$ & $\begin{array}{l}\text { Figura masculina } \\
\text { emblema del niño } \\
\text { que ha actuado } \\
\text { bien durante el } \\
\text { año y merece su } \\
\text { recompensa. }\end{array}$ & & \\
\hline
\end{tabular}

Fuente: anuncio Do you note? My mom sure knows how to shop smart!, (Samsung Mobile, 2014a).

El Sistema Mundo construido para esta campaña refleja la mitología fundacional ${ }^{8}$ de la familia, la cual dentro de su ideal de ser está legitimando el arquetipo de la madre como mujer llena de afectividad hacia sus seres queridos. Su amor materno materializado en una actividad de consumo hace que ella haga uso de un enser hasta hace poco atípico (un Smartphone), manipulando "la tecnología" para consumar su deseo: buscar, encontrar y comprar el detalle perfecto para cada integrante de la familia, y es que su condición socio-simbólica está enfocada a complacer a los demás, brindando estabilidad y felicidad. Por otra parte, el spot muestra el arquetipo del hijo como el ser que razona y valida la condición de la actividad de consumo de la madre al decir que es la "encargada de comprar los regalos" para todos los miembros de la familia. El hijo en esta actividad de razonar también es consciente que la emocionalidad desbordada de la madre afecta la convivencia de la familia; si ella es un caos, su emocionalidad replica en el entorno familiar. Entonces, en este spot publicitario se puede observar en el primer plano del mensaje (plano aparente) la venta de un enser tecnológico que cambia rutinas, sin embargo, la tecnología valida en el plano subyacente (plano paralelo) el régimen ortodoxo de la cultura, al retomar el emblema mitológico de la familia con condiciones socio-simbólicas evidentes en estos dos personajes arquetípicos. 


\section{El hijo "crédulo" por conveniencia}

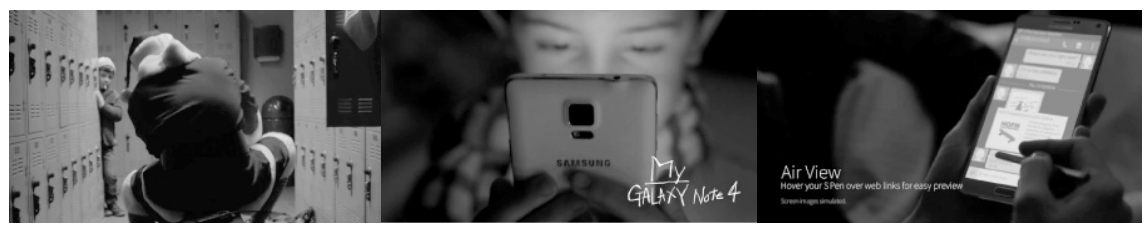

Nota: El niño admite convenientemente que "sigue creyendo en Papá Noel”.
Nota: Evidencia la condición de nativo digital al usar intuitivamente la herramienta.
Nota: El hijo facilita a la madre la compra de su regalo navideño.
Para evidenciar la condición socio-simbólica de los nativos digitales/globales (millennials), se presenta a continuación otro ejemplo de la misma campaña del Galaxy Note 4. En el spot titulado: Do You Note? I Believe in Santa! (Samsung Mobile, 2014b), el cual promociona el lápiz digital como enser tecnológico indispensable para el dispositivo móvil, presenta al hijo menor de la familia (el narrador de esta campaña) como el emblema del niño que al actuar bien tiene su recompensa, ${ }^{9}$ esta construcción se ve reflejada en sus códigos éticos: él justifica que ha actuado bien durante el año y por eso merece el regalo que desea para navidad. Pues bien, el creer en Papá Noel ${ }^{10}$ se convierte en la excusa para tener un beneficio un tanto egoísta, y es que con su voz admite en el relato: "es un tanto extraño que lo mencione pero, sigo creyendo en Papá Noel”. A pesar de saber y verificar que este personaje navideño es un relato inventado por sus padres y por la sociedad, él se adscribe a la "magia consumista" de la época de una manera un tanto inocente y a la vez oportunista, siendo evidente al tomar la bota más grande (talla $\mathrm{XL)}$ para luego decorar "su" árbol de navidad (el árbol familiar) colocando en primer plano esta bota como exigencia de recompensa. Para concluir el ritual del cual se espera el beneficio del obsequio navideño, el niño envía su lista de deseos por medio del Smartphone de su hermana mayor, el cual "robó" temporalmente. El niño al interactuar con el móvil utiliza una aplicación en la que ilustra de manera instintiva la petición navideña (utilizando el enser del lápiz promocionado en el anuncio). Al enviar la imagen, coloca estratégicamente el link de compra del juguete que desea, demostrando que el nativo digital es una persona naturalmente integrada a una lógica de consumo. Cuando el mensaje llega al buzón de los dispositivos móviles de los miembros de la familia, éste se convierte en una petición omnipresente, lo cual es cumplido ${ }^{11}$ cuando la madre hace la compra en línea tras la agradable sorpresa de que su hijo colocó el link de compra en tan conmovedor mensaje, evidenciando de nuevo el arquetipo de la madre dentro del rol femenino de consumo. 
Tabla 2. Registro del código audiovisual

\begin{tabular}{|c|c|c|c|c|c|c|}
\hline \multirow[b]{2}{*}{ Personaje } & \multirow[b]{2}{*}{ Espacio } & \multirow[b]{2}{*}{$\begin{array}{l}\text { Características de } \\
\text { migrante digital }\end{array}$} & \multirow[b]{2}{*}{$\begin{array}{l}\text { Características } \\
\text { de nativo digital } \\
\text { (millennial) }\end{array}$} & \multicolumn{3}{|c|}{ Condiciones de mundo } \\
\hline & & & & $\begin{array}{l}\text { Símbolos } \\
\text { rutinarios } \\
\text { del régimen } \\
\text { ortodoxo }\end{array}$ & $\begin{array}{l}\text { Símbolos } \\
\text { rutinarios del } \\
\text { régimen que } \\
\text { aparentemente } \\
\text { cuestiona la } \\
\text { autoridad }\end{array}$ & $\begin{array}{l}\text { Símbolos } \\
\text { rutinarios del } \\
\text { régimen que } \\
\text { cambia de } \\
\text { estructura }\end{array}$ \\
\hline Hijo & $\begin{array}{l}\text { - Urbano. } \\
\text { - Centro } \\
\text { comercial. } \\
\text { Patio de la } \\
\text { casa. } \\
\text { Sala de la casa. }\end{array}$ & & $\begin{array}{l}\text { Persona que } \\
\text { siempre busca } \\
\text { la verdad, por } \\
\text { lo que tiene } \\
\text { el hábito de } \\
\text { verificar la } \\
\text { información } \\
\text { proporcionada } \\
\text { por la sociedad. } \\
\text { Persona } \\
\text { integrada } \\
\text { a la lógica } \\
\text { capitalista } \\
\text { del consumo, } \\
\text { conoce los } \\
\text { accesos y } \\
\text { procedimientos } \\
\text { de compra del } \\
\text { enser deseado. } \\
\text { Utiliza de } \\
\text { manera } \\
\text { instintiva las } \\
\text { herramientas } \\
\text { tecnológicas. }\end{array}$ & $\begin{array}{l}\text { Figura } \\
\text { masculina } \\
\text { emblema del } \\
\text { niño que ha } \\
\text { actuado bien } \\
\text { durante el año } \\
\text { y merece su } \\
\text { recompensa. } \\
\text { Figura } \\
\text { masculina joven } \\
\text { emblema de } \\
\text { las personas no } \\
\text { creyentes en los } \\
\text { relatos socio- } \\
\text { moralizantes de } \\
\text { la infancia. }\end{array}$ & & \\
\hline Madre & $\begin{array}{l}\text { Urbano. } \\
\text { Recámara de la } \\
\text { casa. }\end{array}$ & \begin{tabular}{|l|} 
Persona que se \\
adapta al uso de \\
las herramientas \\
tecnológicas. \\
Traslada la \\
acción análoga \\
de compra a la \\
plataforma digital. \\
Aún en un \\
mundo altamente \\
tecnologizado, \\
el migrante es \\
una persona \\
crédula de los \\
relatos socio- \\
moralizantes de \\
la sociedad.
\end{tabular} & & $\begin{array}{l}\text { Figura femenina } \\
\text { emblema } \\
\text { de la mujer } \\
\text { consumista, su } \\
\text { razón de ser } \\
\text { es comprar el } \\
\text { objeto perfecto } \\
\text { para cada } \\
\text { integrante de su } \\
\text { familia. } \\
\text { Figura femenina } \\
\text { emblema de la } \\
\text { maternidad. El } \\
\text { personaje revela } \\
\text { por medio } \\
\text { del vínculo } \\
\text { afectivo con } \\
\text { los integrantes } \\
\text { de la familia } \\
\text { el interés de } \\
\text { llenarles de } \\
\text { detalles. }\end{array}$ & & \\
\hline
\end{tabular}

Fuente: anuncio Do You Note? I Believe in Santa! (Samsung Mobile, 2014b). 
El Sistema Mundo construido para este anuncio, de nuevo, nos enfrenta a la mitología fundacional de la familia. Sin embargo, el énfasis brindado en la construcción sociosimbólica del nativo digital (millennial) connota, además, la construcción paradigmática del credo, irónicamente visible en la no creencia de Papá Noel. El arquetipo del hijo es la representación del ser moderno en el cual la razón gobierna sobre cualquier tipo de pensamiento maravilloso. El razonar vuelve a este personaje arquetípico como un ser utilitarista al manipular a conveniencia una creencia popular (él sabe que Papá Noel no existe y que quienes compran los regalos son sus padres), por lo que estratégicamente plantea la "relación oportuna y conveniente" para obtener su recompensa al haber actuado bien durante el año. Este spot también evidencia la condición socio-simbólica de la madre como migrante digital. Esta condición revela que por cuestiones de edad ella está vinculada a principios ideológicos y religiosos de la época (y es que Navidad es un tiempo para consolidar la fe, la unión y el amor), por lo que ella por rol atribuido materializa su necesidad de creer en compartir un detalle físico, el cual debe ser especial y único para cada integrante familiar. Su ser lleno de afectividad y credulidad se ciega ante el gesto "ingenuo" por parte del niño de creer en Papá Noel, cayendo así en la estrategia frívola del hijo.

\section{Los trabajadores excluidos por la tecnología}

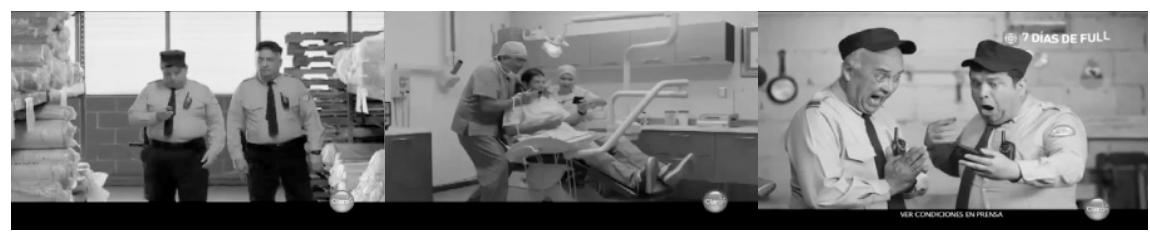

Nota: Los vigilantes no gozan Nota: Profesionales de otras Nota: Aun desconociendo de los beneficios del mundo áreas gozan de los beneficios del internet, su dispositivo y del internet. Hasta cierto el servicio no les permiten punto el spot de televisión es ser partícipes. Esta dificultad un tanto discriminativo con evidencia el tema de la las personas de profesiones Brecha Digital. humildes. el tipo de móvil y tipo de servicio, puesto que el spot de televisión no lo evidencia, los migrantes digitales por un momento pertenecen a la sociedad virtual.

En este punto del artículo atañe la siguiente pregunta: ¿Qué contraste se puede encontrar en la condición socio-simbólica de los nativos (millennials) y migrantes digitales y su construcción de
Sistema Mundo en la publicidad salvadoreña de enseres y servicios tecnológicos? En primer lugar, es importante partir del hecho que en El Salvador esta construcción de nativos y migrantes digitales en la 
publicidad de enseres y servicios tecnológicos es llevada a cabo por las principales empresas de telefonía: Claro, Tigo, Digicel y Movistar. Esto implica que el mundo virtual construido a partir de la condición socio-simbólica de los dos usuarios a nivel local parte de la iniciativa de promover los diferentes beneficios de la navegación por internet, así como la novedad de utilizar ciertas aplicaciones o apps, las cuales facilitan procesos, ayudan a estar siempre comunicados y permiten desarrollar ciertas habilidades de intercambio socio-simbólico y cultural. En este sentido, el anuncio de la empresa telefónica Claro (2014): Cambia de equipo, presenta a dos vigilantes cuyas edades rondan entre los cuarenta y cincuenta años, ellos parecen cuidar una bodega y están pendientes de los resultados de un partido de fútbol. La construcción socio-simbólica ${ }^{12}$ del migrante digital a nivel local es presentada por medio de la figura masculina de dos trabajadores obreros que laboran cuidando una bodega. Es un trabajo modesto en el que ambos llevan una vida tranquila, sedentaria, y sin necesidades aparentes, hasta que ellos intentan ver un partido de fútbol y se dan cuenta que el dispositivo móvil con el que pretenden acceder a la transmisión tiene inconvenientes para conectarse con la señal en directo. Ese instante, el cual muestra la limitante de no poder ver el partido a través del dispositivo, desencadena la necesidad de estar presente virtualmente, ${ }^{13}$ los vigilantes como obreros de baja condición están presos en el espacio de trabajo y están negándose al privilegio del que otros trabajadores profesionistas -de un estatus social más elevado- pueden disfrutar sin ningún problema. El que ellos quieran o no obtener un nuevo dispositivo con un mejor servicio es su limitación o su facultad. Al finalizar el spot, el deber hacer de los vigilantes se torna en adquirir el producto ${ }^{14}$ y de esta manera (aunque momentánea) ellos se vuelven iguales a los otros profesionistas desarrollados, ya que tienen el mismo disfrute de esta "Democracia del Consumo", y ahora están trabajando y disfrutando de una manera feliz, puesto que han satisfecho su objeto de deseo. 


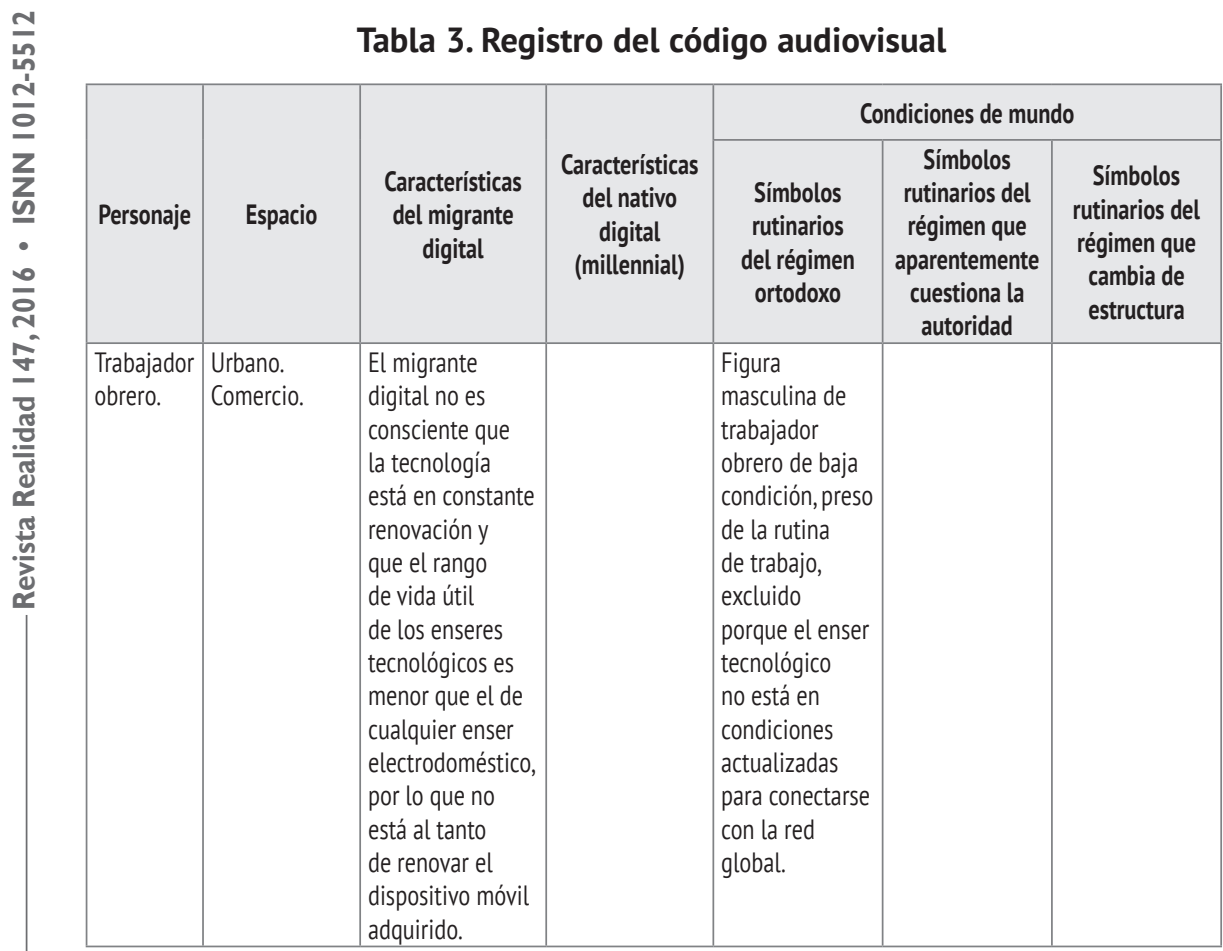

Fuente: anuncio Cambia de equipo (Claro, 2014).

La mitología fundante que hace alusión en este Sistema Mundo es la del trabajo. Sin embargo, esta condición está contrapuesta con la mitología fundante del desarrollo, puesto que la condición socio-simbólica de los migrantes digitales a nivel local está siendo representada por medio de las figuras masculinas de trabajadores modestos, no totalmente desarrollados debido a que son escenificados como seres excluidos y frustrados ya que utilizan una tecnología obsoleta que no les permite ser partícipes de los gozos del mundo virtual. No obstante, es hasta que ellos deciden tener la práctica de consumo de renovación de un dispositivo cuando logran alcanzar el ideal momentáneo de trabajadores obreros desarrollados. En este punto es interesante señalar que el spot hace evidente el tema de la Brecha digital ${ }^{15}$ como problema de índole actual, el cual continúa afectando a países en vías de desarrollo, tal como es el caso de El Salvador. El término brecha digital hace referencia a la separación que existe entre las personas, comunidades, Estados, países que utilizan las tecnologías de la información y la comunicación (TIC) como una parte rutinaria de su vida y aquellas que no tienen acceso a las mismas, y que aunque las tengan no saben cómo utilizarlas (Serrano \& Martínez, 2003). 


\section{El joven geek reflejo de la honestidad}

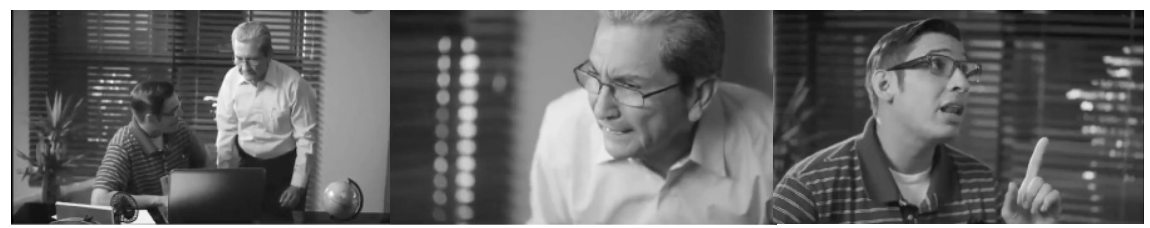

Nota: El nativo digital utiliza términos tecnológicos para explicar el problema ocurrido con la computadora del migrante.
Nota: Emblema del maestro. En sí, la acción del nativo consiste en instruir al migrante, el emblema se ve consolidado con la ubicación del orbe en la parte inferior derecha.
Nota: El migrante digital no entiende el argot del nativo, y considera de una manera pesimista y trágica que la computadora no haya podido encender.
Para visibilizar la condición socio-simbólica del nativo digital local se hace referencia al anuncio de la compañía telefónica Tigo (2014): Transparencia Tigo, el cual presenta a dos figuras masculinas (una adulta de la tercera edad y otra joven) quienes dentro de su ideal de cotidianidad se presentan como personas de clase media donde la figura masculina más joven (nativo digital) está ayudando a la figura masculina adulta (migrante digital) a solventar un problema con su enser tecnológico de escritorio. ${ }^{16}$ En ese estira y encoge de no saber si el dispositivo está arruinado, ${ }^{17}$ el revisar y determinar que solamente estaba descargado ${ }^{18}$ hace que el nativo utilice su argot y explique de manera tecnológica el porqué de las cosas. La escena emula a un joven lleno de conocimientos guiando a un antiguo maestro, ambos personajes mantienen estéticamente un referente hacia la educación, el orbe colocado en la parte inferior derecha lo devela intencionalmente, la presentación personal ordenada, el estar vinculados bajo la misma práctica de valores morales (en el anuncio es visualizado el valor de la honestidad) hace que ambos sean el reflejo del mismo personaje en diferentes épocas. 


\begin{tabular}{|c|c|c|c|c|c|c|}
\hline \multirow[b]{2}{*}{ Personaje } & \multirow[b]{2}{*}{ Espacio } & \multirow[b]{2}{*}{$\begin{array}{c}\text { Características } \\
\text { de migrante } \\
\text { digital }\end{array}$} & \multirow[b]{2}{*}{$\begin{array}{l}\text { Características } \\
\text { de nativo } \\
\text { digital } \\
\text { (millennial) }\end{array}$} & \multicolumn{3}{|c|}{ Condiciones de mundo } \\
\hline & & & & $\begin{array}{c}\text { Símbolos } \\
\text { rutinarios } \\
\text { del régimen } \\
\text { ortodoxo }\end{array}$ & $\begin{array}{l}\text { Símbolos } \\
\text { rutinarios del } \\
\text { régimen que } \\
\text { aparentemente } \\
\text { cuestiona la } \\
\text { autoridad }\end{array}$ & $\begin{array}{l}\text { Símbolos } \\
\text { rutinarios del } \\
\text { régimen que } \\
\text { cambia de } \\
\text { estructura }\end{array}$ \\
\hline $\begin{array}{l}\text { Joven lleno de } \\
\text { conocimientos. }\end{array}$ & $\begin{array}{l}\text { Urbano. } \\
\text { Sala de } \\
\text { estudio del } \\
\text { maestro } \\
\text { adulto de } \\
\text { la tercera } \\
\text { edad. }\end{array}$ & & $\begin{array}{l}\text { Domina el argot } \\
\text { tecnológico } \\
\text { porque } \\
\text { conoce el } \\
\text { funcionamiento } \\
\text { de los } \\
\text { dispositivos. } \\
\text { Es una persona } \\
\text { que posee } \\
\text { conocimientos } \\
\text { y está abierta } \\
\text { a compartirlos } \\
\text { para ayudar } \\
\text { al migrante } \\
\text { en esta nueva } \\
\text { adaptación. }\end{array}$ & $\begin{array}{l}\text { Figura joven } \\
\text { y masculina } \\
\text { poseedor } \\
\text { y dador de } \\
\text { conocimientos. }\end{array}$ & & \\
\hline $\begin{array}{l}\text { Maestro adulto } \\
\text { de la tercera } \\
\text { edad. }\end{array}$ & $\begin{array}{l}\text { Urbano. } \\
\text { Sala de } \\
\text { estudio del } \\
\text { maestro } \\
\text { adulto de } \\
\text { la tercera } \\
\text { edad. }\end{array}$ & $\begin{array}{l}\text { Cree que } \\
\text { los enseres } \\
\text { tecnológicos } \\
\text { son elementos } \\
\text { continuos, al } \\
\text { igual que los } \\
\text { elementos } \\
\text { análogos } \\
\text { (un libro no } \\
\text { necesita cargar } \\
\text { su batería, } \\
\text { una máquina } \\
\text { de escribir } \\
\text { tampoco) por } \\
\text { lo que pasa por } \\
\text { desapercibido } \\
\text { los } \\
\text { elementos de } \\
\text { funcionalidad } \\
\text { de los } \\
\text { dispositivos. }\end{array}$ & & \begin{tabular}{|l|} 
Figura adulta \\
y masculina \\
del maestro. \\
Persona que \\
hereda el \\
conocimiento \\
en el mundo \\
tradicional.
\end{tabular} & & \\
\hline
\end{tabular}

Fuente: anuncio Transparencia Tigo (Tigo, 2014).

El Sistema Mundo de este spot plantea los mitos contrapuestos de la educación y la transmisión de conocimientos. La figura arquetípica del maestro y adulto de la tercera edad connota al personaje que antes 
tenía la autoridad y el conocimiento. Este emblema exaltado por el orbe dicta la lógica jerárquica de la escuela tradicional: el maestro es el emisor de la luz del conocimiento y el alumno es que el que acoge esta iluminación. El postulado se ve contrapuesto ante la aparición en escena de la figura arquetípica del joven lleno de "nuevos" conocimientos, quien perteneciente a una generación distinta se apropia de su condición ventajosa, transmitiendo los conocimientos al maestro que muestra evidentes resistencias al pertenecer culturalmente a la tradición documental de los libros. La situación de reflejo entre ambas figuras arquetípicas genera a nivel cultural un ciclo sin fin: el maestro adulto hereda el conocimiento y el ideal de buen ciudadano al joven, mientras que el joven en el mundo de la "nueva generación" transmite los conocimientos y valores de sus predecesores, retomando así el lugar del maestro.

\section{Algunas conclusiones}

Según el análisis realizado, existe una relación de complicidad entre la publicidad y la perpetuación de las representaciones sociales. Pues bien, al hacer un anclaje teórico este punto tiene el respaldo de Gubern (1987), quien define que la publicidad es la imagen connotada por excelencia: "al objeto representado se le añaden intensos valores o atributos emocionales que transforman la información en sentido" (p. 205), y es que en el caso específico de los spots analizados, éstos visualizan "los arquetipos más apreciados de su tipología social" (p. 201). La publicidad retoma de la sociocultura los arquetipos de la madre, el hijo, los trabajadores, el joven y el maestro, y los devuelve con una narrativa cargada de atributos emocionales, esto con el fin de potenciar la identificación del público objetivo con los personajes cotidianos en el relato mismo.

La narrativa en los cuatro casos mostrados representa condiciones míticas en sus modelos de mundo. Las narrativas retoman los mitos clásicos de la familia, el trabajo y la educación, mitos que revelan raíces connotadas de un afán ortodoxo en la cultura, siendo evidentes en los spots de enseres y servicios tecnológicos analizados. En la siguiente tabla se evidencia la condición y construcción socio-simbólica entre los spots. 


\section{Tabla 5. Condición y construcción socio-simbólica entre lo global y lo local}

\begin{tabular}{|l|c|c|c|c|}
\hline \multicolumn{1}{|c|}{ Nombre del anuncio } & Tipo de usuario & Ubicación & Mitología & Modelo de mundo \\
\hline $\begin{array}{l}\text { Do you note? My mom sure knows how to shop } \\
\text { smart! (Samsung Mobile, 2014a). }\end{array}$ & Migrante digital. & Global. & Familia. & $\begin{array}{c}\text { Creencia y } \\
\text { afectividades. }\end{array}$ \\
\hline $\begin{array}{l}\text { Do You Note? I Believe in Santa! (Samsung Mobile, } \\
\text { 2014b). }\end{array}$ & Nativo digital. & Global. & Familia. & $\begin{array}{c}\text { Creencia y } \\
\text { afectividades. }\end{array}$ \\
\hline Cambia de equipo (Claro, 2014). & Migrante digital. & Local. & Trabajo. & $\begin{array}{c}\text { Progreso y desarrollo } \\
\text { ideal. }\end{array}$ \\
\hline Transparencia Tigo (Tigo, 2014). & Nativo digital. & Local. & Educación. & $\begin{array}{c}\text { Transmisión de } \\
\text { conocimientos. }\end{array}$ \\
\hline
\end{tabular}

Pues bien, el Sistema Mundo entre nativos (millennials) y migrantes digitales que se vislumbra en los primeros tres casos presenta relaciones segmentadas. La mitología fundacional de la familia propone en primera instancia la alegoría $^{19}$ al consumo escenificada por medio de las actitudes y comportamientos de la migrante digital/global. En segunda instancia, esa mitología vislumbra la relación oportunista del nativo digital/ global que ha crecido en un mundo más impersonal y mecanizado, y se antepone a la de credulidad e ingenuidad de la migrante, quien tiene amarres con las tradiciones. Por otra parte, en el caso de los migrantes digitales/locales (vigilantes), el Sistema Mundo revela la mitología fundacional del desarrollo; aunque es un desarrollo condicionado y efímero debido a que momentáneamente se ven igualados a los otros profesionistas cuando acceden a los gozos de los nuevos beneficios de la tecnología, sin embargo, obreros y profesionistas siempre serán diferentes en sus condiciones de clase.

En contraste, el último caso de Tigo (2014) quizás es el más honorable del Sistema Mundo entre nativos y migrantes digitales, lo que hace por lo visto al mito fundacional de la educación como una de las principales riquezas del ser humano. A pesar que hay una inversión del mito (en el mito original el anciano es el sabio y el joven es el que aprende), éste está indicando que la juventud en el "nuevo mundo" por medio de otros lenguajes y habilidades también es capaz de enseñar una nueva manera de ver lo mismo: una cultura de valores basada en códigos honestos.

Los spots son homogeneizadores, no evidencian el problema de la brecha digital literalmente. Quizás el anuncio Cambia de equipo de la telefonía Claro (2014) podría encarrilarse en este sentido. Sin embargo, al final del spot, las dos personas trabajadoras llegan a su ideal: acceder al servicio renovando su móvil. Aun así en el paradigma de la sociedad virtual: ¿qué pasa con los que no tienen acceso a los servicios y enseres por las desigualdades sociales? Al parecer, la publicidad en su intento de vender un ideal de estatus por medio del consumo "invisibiliza" a este tipo de personas. 
Al final, tras la capa de la innovación del servicio o del enser, se vislumbra el objetivo de vender el producto por medio de sus arquetipos preconcebidos, los cuales en el mensaje reproducen patrones de años atrás: la mujer que consume, el niño vivaz, entre otros. Por lo que la representación virtual de la sociedad pareciera ser la misma que la de usos de enseres análogos. El discurso al final no cambia: este discurso legitima los modelos de mundo ya establecidos por medio de sus arquetipos.

\section{Referencias}

- Cerezo, J. M. (30 de noviembre de 2015). Hacia un nuevo paradigma. La era de la información fragmentada. Recuperado de http://tinyurl.com/jkkoupr

- Claro. (2014). Cambia de equipo. Recuperado de https://www.youtube. $\mathrm{com} /$ watch? $\mathrm{v}=\mathrm{jbB} 3 \mathrm{nNn} 5 \mathrm{yQ}$

- Durand, G. (1964). La imaginación simbólica. Argentina: Editorial Amorrortu.

- Greimas, A. J. (1973). Semántica estructural: investigación metodológica. Madrid: Gredos.

- Gubern, R. (1987). La mirada opulenta. Exploración de la iconosfera contemporánea. Barcelona, España: Editorial Gustavo Gili.

- Hinkelammert, F. (2007). Crítica de la razón mítica. El laberinto de la modernidad: la polarización fundamental en el cristianismo. San José, Costa Rica: Editorial Arlekín.

- Prensky, M. (2010). Nativos e inmigrantes digitales. Madrid: Institución Educativa SEK.

- Samsung Mobile. (2014a). Do you note? My mom sure knows how to shop smart! Recuperado de https://www.youtube.com/watch?v=GTGaVe6c-hw

- _ _ (2014b). Do You Note? I Believe in Santa! Recuperado de https:// www.youtube.com/watch?v=FpzDitrM8Uc

- Serrano, A. \& Martínez, E (2003). La brecha digital: mitos y realidades. México: Editorial UABC.

- Tigo. (2014). Transparencia Tigo. Recuperado de https://www.youtube.com/ watch?v=xPzJUDfMoH4 
$1 \quad$ Nativos digitales es el nombre brindado por Prensky (2010) a aquellos jóvenes cuya lengua materna es la de los ordenadores, videojuegos e internet.

2 Migrantes digitales es el nombre brindado por Prensky (2010) a todas aquellas personas que se han incorporado al mundo digital.

3 Se entenderá "Sistema Mundo" como la adecuación del término de Gilbert Durand "concepción de mundo" (Weltbild, en alemán), el cual hace referencia a los grandes sistemas de imágenes de representación de mundo (Durand, 1964, p. 97). Estos sistemas comprenden una construcción socio-simbólica que se perpetúa a través de diversos canales: los credos, la educación tutelada y la familia.

4 Esta condición socio-simbólica hace referencia al "querer ser" del modelo actancial de Algirdas Julius Greimas (1973, pp. 262-291). En el caso del spot publicitario, es el personaje presentado por medio del estereotipo.

5 El emblema es un signo de tipo complejo que representa a un personaje que está rodeado o utiliza distintos objetos. (Durand, 1964, p.12).

6 Esta condición socio-simbólica hace referencia a el "querer poder" del modelo actancial de Algirdas Julius Greimas, esa fuerza capaz de entorpecer o facultar al relato, la narración, y que influye en éste de manera simbólica.

7 Esta condición socio-simbólica hace referencia al "querer tener" del modelo actancial de Greimas. Es el deseo obtenido, el logro prometido, el horizonte donde el personaje tiene que llegar como gratificación.

8 Se entenderá "Mitología Fundacional - Mitos fundantes" a la adecuación sobre aquellos arquetipos, formas dinámicas que estructuran u organizan las imágenes (Durand, 1964, p. 72), los cuales elaboran marcos categoriales de un pensamiento frente a la contingencia del mundo (Hinkelammert, 2007, p. 67). Es decir, los Mitos Fundantes son aquellos modelos arquetípicos que la condición ideal de sociedad establece como formas de aprendizaje sociomoralizante, ya sean restrictivos 0 posibilitantes de una conducta.

9 Esta condición socio-simbólica hace referencia al "querer ser" del modelo actancial de Greimas.

10 Esta condición socio-simbólica hace referencia a el "querer poder" del modelo actancial de Greimas.

11 Esta condición socio-simbólica hace referencia al "querer tener" del modelo actancial de Greimas.

12 Esta condición socio-simbólica hace referencia al "querer ser" del modelo actancial de Greimas.

13 Esta condición socio-simbólica hace referencia a el "querer poder" del modelo actancial Greimas.

14 Esta condición socio-simbólica hace referencia al "querer tener" del modelo actancial Greimas.

15 Tal como lo menciona Cerezo (2008), la Brecha digital es un problema dentro del contexto de acceso a la información.

16 Esta condición socio-simbólica hace referencia al "querer ser" del modelo actancial de Greimas.

17 Esta condición socio-simbólica hace referencia a el "querer poder" del modelo actancial Greimas.

18 Esta condición socio-simbólica hace referencia al "querer tener" del modelo actancial Greimas.

19 Se entenderá como "alegoría" al signo que presenta a un personaje escenificado haciendo una acción. (Durand, 1964, p. 12). 